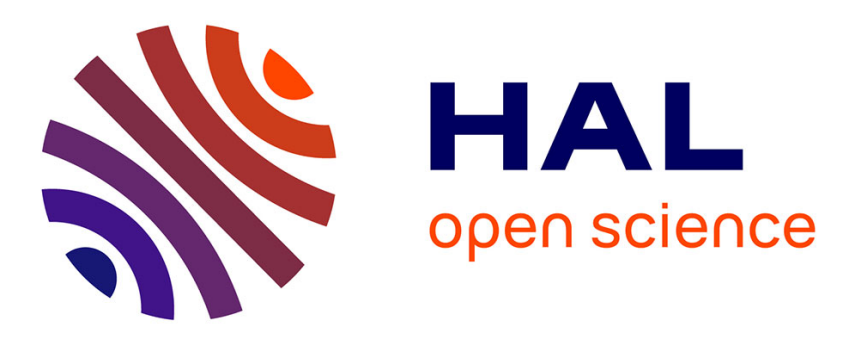

\title{
Planning and monitoring of stored malting barley quality maintenance
}

\author{
Seydina M. Ndiaye, Amadou Ndiaye, Francis Fleurat-Lessard
}

\section{To cite this version:}

Seydina M. Ndiaye, Amadou Ndiaye, Francis Fleurat-Lessard. Planning and monitoring of stored malting barley quality maintenance. Modelling and Control in Agriculture, Horticulture and Postharvested Processing, 2001, Wageningen, Netherlands. hal-01219535

\section{HAL Id: hal-01219535 \\ https://hal.science/hal-01219535}

Submitted on 22 Feb 2017

HAL is a multi-disciplinary open access archive for the deposit and dissemination of scientific research documents, whether they are published or not. The documents may come from teaching and research institutions in France or abroad, or from public or private research centers.
L'archive ouverte pluridisciplinaire HAL, est destinée au dépôt et à la diffusion de documents scientifiques de niveau recherche, publiés ou non, émanant des établissements d'enseignement et de recherche français ou étrangers, des laboratoires publics ou privés. 


\title{
PLANNING AND MONITORING OF STORED MALTING BARLEY QUALITY MAINTENANCE
}

\author{
Seydina M. Ndiaye, Amadou Ndiaye ${ }^{1}$ and Francis Fleurat-Lessard
}

\author{
INRA, Laboratoire des Insectes des Denrées Stockées \\ B.P. 81, F 33883 Villenave d'Ornon, France \\ tel.: +33 (0) 556843 290, fax: +33 (0) 556843289 \\ I email: an@bordeaux.inra.fr
}

\begin{abstract}
Representing the stored grain ecosystem for quality maintenance implies the representation of all its characteristics that take part in the grain quality degradation process. A mixed qualitative and quantitative modelling is used to represent the stored grain ecosystem. The temperature, moisture content and presence of insects are used as control variables. The quality maintenance operations are represented as actions to be executed in time requiring available equipment and consumable. Our planning approach involves three consecutive stages: treatment to obtain a safe grain storage condition, storage to maintain the storage condition and dispatch to respond to the market requirements. Copyright $(2000$ IFAC
\end{abstract}

Keywords: Computer, Modelling, Knowledge-based control, Planning, Monitoring, Agriculture

\section{INTRODUCTION}

Building up decision support systems (DSS) for the conservation of grain initial quality during the storage period is one of the major concerns of postharvest research. Storage proves to be the weak link in foodstuff quality chain. Modern farming technics have allowed an increase in the world production of cereals; and, consequently, an increase in storage capacities and duration. It so happens that any lengthening of storage duration means an increase in the risk of grain degradation. Grain is a living organism, and the normal outcome of its vital activity is germination and oxidation phenomena (Multon et al., 1969). A stock of grain is the natural environment of insects, mites, and micro organisms: insects and mites consume and spoil the grain (Fleurat-Lessard et al., 1994a), while microorganisms deteriorate and contaminate it (Cahagnier et al., 1993).

In the stored grain ecosystem the biotic variables (grain, insects, moulds and mites) interact with abiotic variables (temperature, moisture content, impurities, atmospheric composition) which are influenced by the environmental conditions of the storage location. Much of the knowledge required to maintain stored grain quality is fragmented and applied in different ways, with varying success. The use of a computerised knowledge based decision support system could improve the conservation of stored grain in: i/ the assessment of the grain quality and condition at delivery; ii/ the planning of the grain storage in time taking into account the equipment and consumable; iii/ the monitoring of the storage condition during plan execution in order to be able to replan the storage if something goes wrong.
The interest of building up a knowledge based system to take up this problem can be explained by the strongly experimental nature of the available knowledge. For example, the population growth rates are known only for certain insect pests, at certain temperatures and humidity and for certain grains (Beckett et al., 1994). During the last ten years, several knowledge based pest control systems have been built up to support the control of stored grain pests (insects and mites) (Flinn et al., 1990), (Wilkin et al., 1991), (Longstaff et al., 1994), (Pasqual \& Mansfield, 1988), (Jones et al., 1993). These systems have confirmed the interest of DSS to help preserve grain on one hand, and, on the other hand, have shown the limits of pest control as far as grain quality maintenance is concerned. Today, current research focuses on preservation of grain initial quality (Ndiaye et al., 1997, 1998).

Our aim is a prevention of grain quality degradation guided by the measured values of the environmental factors and the noises from insects. The studies on environmental factors show that they give an early information on the risks of quality degradation (Fleurat-Lessard et al., 1994b; Wrigley et al. 1994; Juliano, 1994). Our approach differs from existing systems in that we give priority to the prevention of grain initial quality degradation, and therefore to predictive signs of degradation. Our strategy is based on an assessment of grain initial quality in order to be able to determine the optimal storage technical route allowing us to monitor the quality of grain. It involves the following three stages: 1) to assess the grain initial quality and condition before storage, 2) to plan an optimal storage technical route, 3 ) to monitor the evolution of grain quality during storage in order to react to any event representing a foreseen or effective quality 
degradation by replanning the storage technical route.

In this paper we present the modelling of the planning and monitoring of malting barley initial quality maintenance during storage period.

\section{MODELLING OF THE ECOSYSTEM OF STORED MALTING BARLEY}

The representation of the ecosystem of malting barley grain stock is rather complex. This complexity is related to the fact that various events interact during storage and can be factors of stock deterioration. These events depend on the various variables composing the ecosystem and the relations which connect them. Thus, to represent the instant status of the grain ecosystem requires representing all the components of the ecosystem and the relations connecting them. Moreover, it is necessary to represent the evolution of the ecosystem during storage. In addition, in order to obtain a total modelling of the grain ecosystem throughout time, we need to represent possible actions on the ecosystem.

An overview of the ecosystem modelling is represented in the figure below. Some variables are evaluated at the beginning of storage and do not evolve through time (quantity, identity). Others evolve during storage and are modified by events and/or actions on the stock (impurities rate, quality, temperature, moisture content, mites, moulds, insects, germination). We have mathematical models which make it possible to calculate the 'natural' evolution (i.e., without unforeseen event or human intervention) of some variables during storage (moisture and temperature, insects, moulds, mites and germination). The evolution of the other variables through time, in response to the events or the actions, is given by expert knowledge.

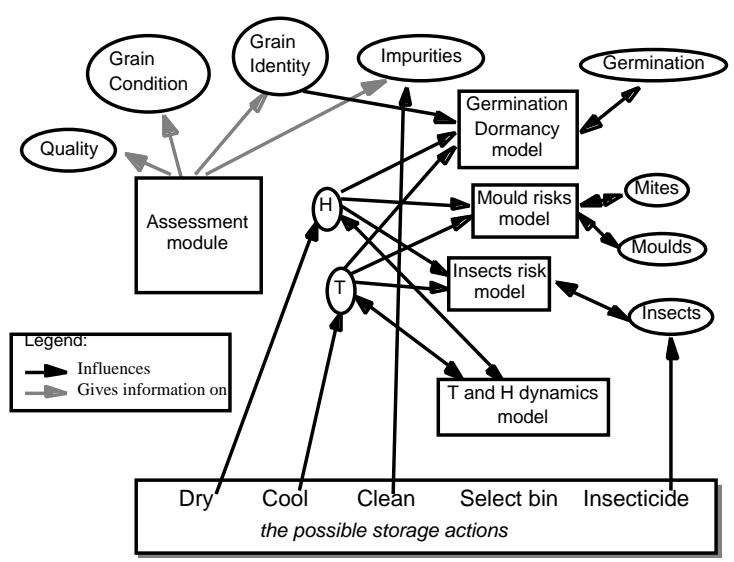

Figure 1. Overview of the ecosystem modelling and possible human interventions.

The model of the grain ecosystem that we present in this section is composed of:

- a representation of state variables;

- mathematical models and expert decision rules for events and changes of some variables (control variables and deterioration variables);

- a representation of actions (human interventions).
In the later sections of this paper, we present the various components of the grain ecosystem and their interactions, then we see how the model is used in the system of grain quality conservation during storage.

\subsection{Representation of ecosystem's state}

Representing state of the grain ecosystem, in the conservation of stored malting barley quality problem, involves representing all the characteristics of the ecosystem which take part in the quality degradation process during storage. By quality deterioration, we mean $1 /$ a degradation of physiological grain quality (including increase of germination, growth of moulds and mites) and $2 /$ a too large ${ }^{1}$ amount of impurities and insects (living or dead) in the stock. According to Multon (Multon, 1988), there are four major spoilage risks of the physiological grain quality: insects ${ }^{2}$, microorganisms (i.e., moulds), Maillard reactions, and oxidation. Multon stated also that these risks depend on the levels of temperature (T) and moisture content (MC) which thus define a stability zone for each risk. In a previous work (Ndiaye, 1998), we have found five polynomial equations which formalise these stability zones ${ }^{3}$ :

Insects: $T=a H^{4}+b H^{3}+c H^{2}+d H+g$ with $\mathrm{T} \leq 27^{\circ} \mathrm{C}$ or $\mathrm{T}>27^{\circ} \mathrm{C}$ (two equations);

Micro-organisms: $H=a T^{3} b T^{2}+c T+d$

with $H \leq 28 \%$ and $T \leq 75^{\circ} \mathrm{C}$;

Maillard reactions: $T=a H^{4}+b H^{3}+c H^{2}+d H+g$ with $\mathrm{T} \leq 75^{\circ} \mathrm{C}$;

Oxidation: $H=a T^{3}+b T^{2}+c T+d$ with $H \geq 5 \circ$ and $T \leq 75^{\circ} \mathrm{C}$.

Thus, managing temperature and moisture content is sufficient to control the physiological grain quality degradation process.

The amounts of impurities and insects are managed by the variables impurity rate (IR), and amount of insects (I).

These four variables (T, MC, IR and I) are called control variables. However, there are other variables which are included in the representation of the ecosystem's state. There are the identity of grain (Id), the quantity of grain (qt), the quality of grain, Q (which has a qualitative value; see (Ndiaye et al, 1998) for more details), the moulds growth (Mo), the presence of mites (Mi), and the germination $(\mathrm{G})$.

We use qualitative representation for managing control variables T, MC, IR and I. For T and MC, we consider three possible values: safe, risky, good and bad; and two values for IR and I: 0 , in the absence of insects or if level of impurities is lower than a threshold $\left(I R_{S}\right)$, and 1 , otherwise. After a

\footnotetext{
${ }^{1}$ The amount of insects or impurities is considered too large when a threshold value is exceeded.

${ }^{2}$ Let us notice that the insects risk here represents the risk of the degradation caused by the insects and not their presence itself.

${ }^{3}$ Variables a, b, c, d and g have different values in each equation (Ndiaye, 1998).
} 
human intervention, values of control variables are updated according to some expert rules or through an assessment ${ }^{4}$.

The state variables can be managed through mathematical models and decision rules given by experts.

\subsection{Mathematical models and expert decision rules}

These models depend on temperature and moisture content. There are three models:

- the insects model, developed by P.W. Flinn, is an algorithm which gives the amount of insects at the end of storage period according to an initial amount of insects, a given temperature and a given moisture content. As defined, this model is not directly usable in our problem because we would like to know when the amount of insects will be considered too large in real storage condition (evolving temperature and moisture content). Thus, we modify it in order to have the amount of insects after a short period of time. The principle is to subdivide the storage period in small time duration and to apply the model for each small time duration. At each application of the model there is a new value of temperature and moisture content. This way, we can compute iteratively the amount of insects and know when it exceeded a threshold;

- the micro-organisms model is a model allowing to calculate the risk of presence of moulds and the maximum duration of conservation which is associated to it. The threshold is the appearance of visible moulding. This model is represented in the form of expert decision rules depending on the activity of water (Aw). The latter can be calculated starting from the moisture content, using an equation developed in (Denne, 1988). This knowledge base integrates data relating to the growth of the principal storage moulds. The effects of the growth of storage moulds (primarily Penicillium and Aspergillus) are also modelled. The main effect is the production of ergosterol (biochemical marker). The relation between the activity of water (Aw) and the maximum storage time is also integrated in the model.

- the temperature and moisture content evolution model is a set of mathematical formula. These equations result from the work of Singh and Thorpe (Singh \& Thorpe, 1993; Thorpe, 1995) on heat and moisture transfer in grain bulks.

All the components of the ecosystem have been defined. We foresee the evolution of the ecosystem during storage by applying to the initial state all the models and by updating state variables.

Now that all the possible events during storage are modelled, it is necessary to have a model of the effects of each action on the ecosystem, mainly on the four control variables.

\footnotetext{
${ }^{4}$ The assessment gives quantitative values which are translated in qualitative values.
}

\subsection{Representation of actions}

As quoted in Figure 1, we have five actions to control storage: drying, cooling, cleaning, select_bin and insecticide.

At a given time, the choice of the action to execute is done according to the current state of the ecosystem and the availability of the resources (instrument and consumable).

In the representation of actions, a major problem is to take into account the time: for each action, the duration of its execution and the duration of its effects. Thus, we have defined three types of actions as shown in Figure 2. In action modelling, the time is represented as a 3-uples:

(time ActionDuration EffectsDuration).

\begin{tabular}{|c|c|c|c|}
\hline $\begin{array}{l}\text { Duration of } \\
\text { the action }\end{array}$ & $\begin{array}{l}\text { Duration of } \\
\text { the effects }\end{array}$ & $\begin{array}{l}\text { Storage } \\
\text { operations }\end{array}$ & $\begin{array}{l}\text { Representation } \\
\text { of time }\end{array}$ \\
\hline $\begin{array}{l}\text { instantaneous } \\
\text { instantaneous } \\
\text { noninstantaneous }\end{array}$ & $\begin{array}{l}\text { permanent } \\
\text { nonpermanent } \\
\text { nonpermanent }\end{array}$ & $\begin{array}{l}\text { \{drying, select-bin }\} \\
\text { insecticide,cleaning } \\
\text { \{cooling }\end{array}$ & $\begin{array}{l}\text { (time } \varepsilon \infty) \\
(\text { time } \varepsilon \text { de) } \\
\text { (time da de) }\end{array}$ \\
\hline
\end{tabular}

Figure 2. Time in action representation.

In this section, we present how the five actions introduced above are modelled, including conditions for application and effects of each of them, and the duration of their application and their effects.

\section{Drying}

The action of drying is carried out when:

* moisture content is too high (threshold value, $m c_{s}$, defined for each country) independently of the temperature (which is considered brought back to a normal value before the application of drying);

* or when there is a too large amount of moulds (higher than a threshold, $m o_{S}$ ).

After drying, the moisture content variable is at a known value (which is fixed beforehand, relative with the country considered) and mould growth is inhibited.

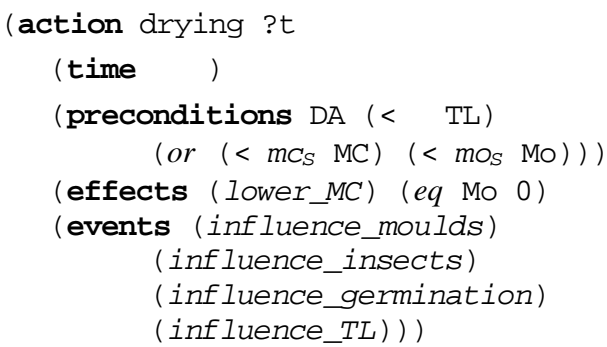

The drying action, as represented above, can be applied at a moment ?t with a duration $\varepsilon$, very small and an effect duration we note $\infty$. Such an action is called instantaneous action with permanent effect. The preconditions are represented as propositions which should be true before action 'drying' is selected, there are 'Dryer available' (DA), moisture content greater than threshold, growth of mould, time left before degradation (TL) greater than the action duration. Note that the time left is the minimum value of three variables: $\mathrm{TL}_{\mathrm{I}}$ 
(time left before a degradation related to insects), $\mathrm{TL}_{\mathrm{Mo}}$ (time left before a degradation related to moulds) and $\mathrm{TL}_{\mathrm{G}}$ (time left before a degradation related to germination). The effects obtained are a reduction in moisture content and a disappearance of moulds. Some events follow which are computation of the various time left. If action drying is applied at time then the new state of the ecosystem is obtained at time $? t+\varepsilon$.

\section{Cooling}

This action prevents the development of moulds and insects. Cooling has effect on temperature and the moisture content (in a less amplitude) of the stock of grains. It should be noticed that if the outside temperature is definitely lower than that of the grain, it can generate condensations on the bin walls that can cause a degradation of grain (in the case of blowing aeration, which is not true for sucking aeration). The duration of cooling depends on the outside temperature, on temperature of the stock of grains and on the air flow specific rate $\left(\mathrm{m}^{3}\right.$ air per $\mathrm{m}^{3}$ grain per hour). The value of the temperature reached can be computed starting from the data relating to the mode of cooling.

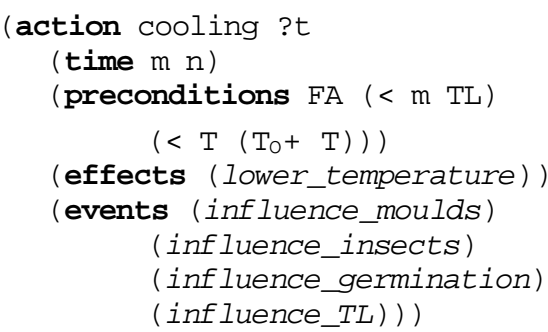

Cooling is a noninstantaneous action with nonpermanent effects. At time ? $\mathrm{t}+\mathrm{m}+\mathrm{n}$, all the effects disappear. The pre-conditions here are: fan available (FA), time left greater than application duration and temperature less than outside temperature plus a fixed value $\Delta \mathrm{T}$.

\section{Cleaning}

This action requires a cleaner (CA: cleaner available). It makes it possible to remove the broken grains and the various impurities. It is an instantaneous action with permanent effects. It is carried out when there is a too large impurities rate $(\mathrm{IR}=1)$. Temperature and moisture content remain constant at the end of cleaning.

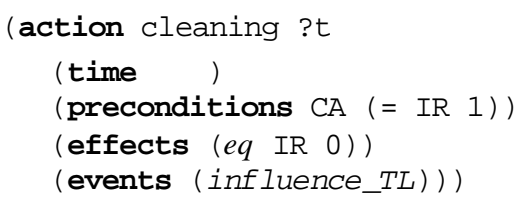

\section{Select-bin}

This action makes it possible to fix the type of bin in which storage will be made. Thus, only some actions will be later acceptable according to the selected type of bin. This choice depends on the identity, the quantity, the initial quality of the grain and the emptiness of the bin.

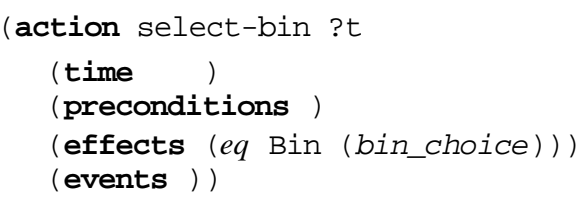

Insecticide

The choice of insecticide to be applied depends on the species of devastating insects of the grain, which vary according to the local climates. Another parameter is the storage period considered. Of course, it is necessary to take into account the list of available and authorised insecticides. The effect of an insecticide can be instantaneous, in the case of an insecticide with shock effect (protection from 1 to 2 weeks against the insects), or a long-term effect, in the case of a long-term insecticide (protection from 4 to 6 months). Applying insecticide has no direct effect on temperature and moisture content. However, the number of insects is brought back to a null value. A negative effect of the application of insecticide is the presence of active insecticide residues which can influence the quality of the grain. Insecticide can also be applied in order to enlarge the time left by increasing the optimal duration of conservation (if no other action is possible).

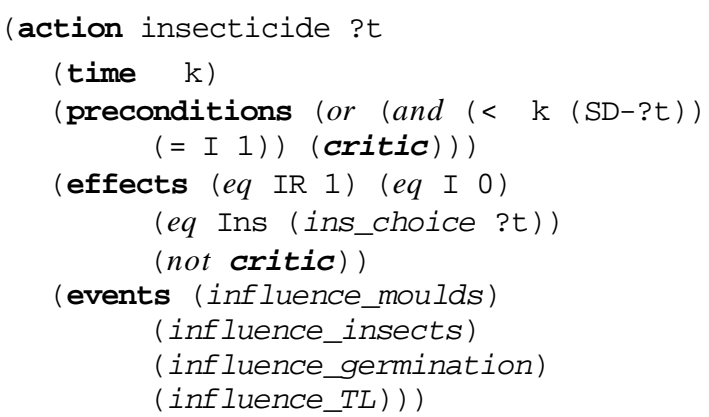

The applying of insecticide is an instantaneous action with nonpermanent effects; it is advocated when there are insects and the effects of insecticide should not remain at the exit of storage, or when no other action is applicable and TL is very low (i.e., critical situation, critic).

These five actions are used to manage the storage process. Figure 3 shows how they influence control variables and then the ecosystem as a whole. The influences of control variables on action choice are also represented. The terms ?, $\downarrow, \uparrow$ and - are respectively 'no information', 'decrease', 'increase' and 'not applicable'

Until now we showed how the ecosystem of the grains stock is modelled, along with a representation of all the actions. We will see in the next section an overview of the general system of generation of action plan for the control of the malting barley storage. 


\begin{tabular}{|c|c|c|c|c|}
\cline { 2 - 5 } \multicolumn{1}{c|}{} & $\begin{array}{c}\text { Temperature } \\
\text { (T) }\end{array}$ & $\begin{array}{c}\text { Humidity } \\
(\mathrm{H})\end{array}$ & $\begin{array}{c}\text { Insects } \\
(\mathrm{I})\end{array}$ & $\begin{array}{c}\text { Impurities } \\
(\mathrm{IR})\end{array}$ \\
\hline Drying & $?$ & $\downarrow$ & - & - \\
\hline Cleaning & - & - & - & $\downarrow$ \\
\hline Select bin & - & - & - & - \\
\hline Insecticide & - & - & $\downarrow$ & $\uparrow$ \\
\hline Cooling & $\downarrow$ & - & - & - \\
\hline
\end{tabular}

\begin{tabular}{|c|c|c|c|c|c|c|c|}
\hline $\mathrm{T}$ & & $\mathrm{H}$ & & I & & IR & \\
\hline $\begin{array}{l}\text { good } \\
\text { risky } \\
\text { bad }\end{array}$ & $\begin{array}{l}\text { cooling } \\
\text { cooling }\end{array}$ & $\begin{array}{l}\text { good } \\
\text { risky } \\
\text { bad }\end{array}$ & $\begin{array}{l}\text { Drying } \\
\text { Drying }\end{array}$ & 1 & Insecticide & $\begin{array}{l}0 \\
1\end{array}$ & Cleaning \\
\hline
\end{tabular}

Figure 3. The influences actions/variables.

\subsection{Overview of the control system}

The aim of the system is to generate a strategy for conservation of stored malting barley quality. Within our system, a strategy is defined in three stages:

- processing (before setting in bin);

- storage and monitoring;

- dispatch (at output of bin and sending).

At each stage, there are some applicable actions, as we can see in the figure below.

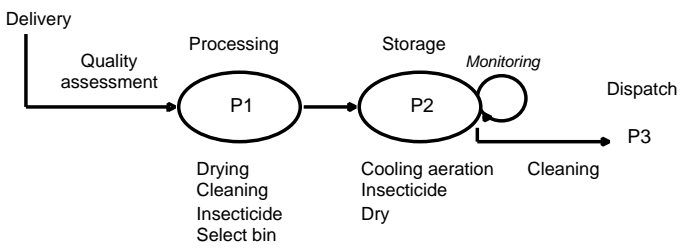

Figure 4. The different process stages of the conservation of stored malting barley.

We plan to use planning and monitoring technics for the generation of a storage strategy.

The general system is composed of a planning module and of a monitoring module. The former works out an initial action plan which is carried out. If an unforeseen event is detected by sensors during the execution of the plan, the planning module is reactivated.

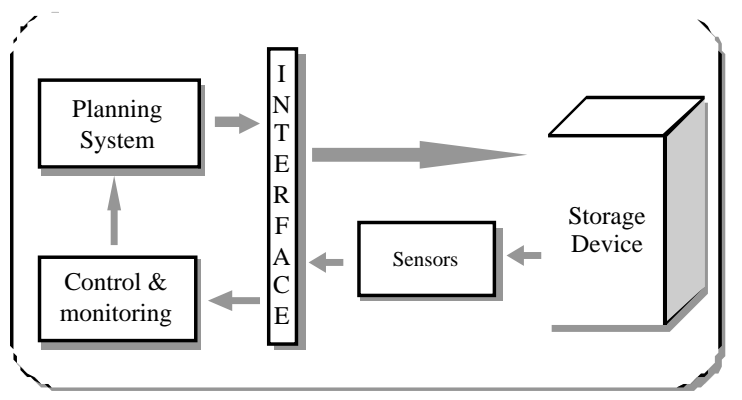

Figure 5. Planning and Monitoring approach.

\section{CONCLUSION}

In this paper we have presented a mixed modelling (qualitative and quantitative) of the ecosystem of stored malting barley, including the possible storage actions. This modelling based on the existing knowledge in grain storage domain, allows us to be able to integrate any new knowledge in this domain.

An implementation of the planning system is on going on a PC computer under Windows ${ }^{\circledR}$ using CLIPS and Common Lisp programming languages.

However, further experimental work is needed to expand the domain of this modelling to other kinds of cereal grain for food end-use.

\section{Acknowledgements}

This work has been carried out with financial support from the Commission of the European Communities, Agriculture and Fisheries (FAIR) specific RTD programme, CT97-3648, "Quality of stored Grain (QualiGrain)". It does not necessarily reflect its views and in no way anticipates the Commission's future policy in this area.

The authors wish to thank Dr Paul Flinn for the insects model provided.

\section{REFERENCES}

Beckett S.J., Longstaff B.C., Evans D.E., (1994). A comparison of the demography of four major stored grain coleopteran pest species and its implications for pest management. Proceedings 6th Int. Working Conf. Stored Product Protection, Canberra, April 94, 1, 4991-497. CAB International, Wallingford.

Cahagnier B., Lesage B., Richard-Molard D., (1993). Mould growth and conidiation in cereal grains as affected by water activity and temperature. Letters in Applied Microbiology, 17, 7-13.

Denne T., (1988). An expert system for stored grain pest management. PhD Thesis The Imperial College of Science and Technology, University of London.

Fleurat-Lessard F., Andrieu A.J., Wilkin D.R., (1994a). New trends in stored-grain infestation detection inside storage bins for permanent infestation risk monitoring. Proceedings 6th Int. Working Conf. Stored Product Protection, Canberra, April 94, 1, 397-402. $\mathrm{CAB}$ International, Wallingford.

Fleurat-Lessard F., Just D., Barrieu P., Le Torc'h J.M., Raymond P., Saglio P., (1994b). Effect of modified atmosphere storage on wheat seed germination vigour and on physiological criteria of the ageing process. Proceedings 6 th Int. Working Conf. Stored Product Protection, Canberra, April 94, 2, 695-700. CAB International, Wallingford.

Flinn P.W., Hagstrum D.W., (1990). Stored Grain Advisor: a knowledge-based system for management of insect pests of stored grain. AI Applications, 4, 44-52. 
Jones T.H., Mumford J.D., Compton J.A.F., Norton G.A., Tyler P.S., (1993). Development of an expert system for pest control in tropical grain stores. Postharvest Biology and Technology, $\mathrm{N}^{\circ} 3$, pp. 335-347.

Juliano B.O., (1994). Concern for quality maintenance during storage of cereals and cereal products. Proceedings 6th Int. Working Conf. Stored Product Protection, Canberra, April 94, 2, 663-665. CAB International, Wallingford.

Longstaff B.C., Cornish P., (1994). PestMan: A decision support system for pest management in the Australian central grain-handling system. AI Applications, 8, 13-23.

Multon J.-L., (1988) Spoilage mechanisms of grains and seeds in the post-harvest ecosystem, the resulting losses and strategies for the defenseof stock. in Preservation and Storage of Grains, Seeds and their Byproducts, Multon Ed., 3-63. Lavoisier publisher

Multon J.-L., Poisson J., Guilbot A., (1969) Les altérations du grain de blé après la récolte. Bulletin Technique d'Information, 244, 1-18.

Ndiaye A., (1998). Recherche de variables composites pour l'aide au contrôle des processus d'altération de l'orge de brasserie pendant le stockage, avant la première transformation. Internal Report, INRA-LIDS.

Ndiaye A., Péron L., Fleurat-Lessard F., (1998) QualiS: Preservation of stored grain quality, diagnosis and grading of wheat grain initial quality. Proceedings Bio-Decision 98, International Conference on Engineering of
Decision Support Systems in Bio-Industries, Monpellier, Feb. 98 (CD-ROM), 12 pages.

Ndiaye A., Péron L., Fleurat-Lessard F., (1997). Diagnosis and Grading of Grain Initial Quality. Proceedings 3rd International Workshop on Mathematical and Control Applications in Agriculture and Horticulture, Hannover, Sept. 97. 219-224.

Pasqual G.M., Mansfield J., (1988). Development of a Prototype Expert System for Identification and Control of Insect Pests. Computers and Electronics in Agriculture, 2, 263-276.

Singh A.K., Thorpe G.R., (1993). A Grid generation technique for numerical modelling heat and moisture movement in peaked bulks of grain. Journal of Food Process Engineering, 16, 127-145.

Thorpe G.R., (1995). More complete mathematical descriptions of heat and moisture transfer in ventilated bulks of respiring grains. Journal of the Society for Engineering in Agriculture, 224.

Wilkin D.R., Mumford J.D., Norton G., (1991). The role of expert systems in current and future grain protection. Proceedings 5th Int. Working Conf. Stored Product Protection, Bordeaux, Sept. 90, 3, Fleurat-Lessard \& Ducom Ed., 2039-3046.

Wrigley C.W., Gras P;W., Bason M.L., (1994) Maintenance of grain quality during storage prediction of the conditions and period of 'safe' storage. Proceedings 6th Int. Working Conf. Stored Product Protection, Canberra, April 94, 2, 666-670. CAB International, Wallingford. 